\title{
Simultaneous Spectrophotometric Determination of Orthophosphate and Silicate Ions in River Water Using Ion- Exclusion Chromatography with an Ascorbate Solution as Both Eluent and Reducing Agent, Followed by Postcolumn Derivatization with Molybdate
}

\author{
Nobutake NaKaTani, *† Wakako MaSuda,* Daisuke KozaKI,* Ryozo Goto,* Nobukazu NaKagoshI,* \\ Masanobu MorI, ${ }^{* *}$ Kiyoshi HASEBE, $* * *$ and Kazuhiko TANAKA* \\ *Graduate School for International Development and Cooperation, Hiroshima University, \\ 1-5-1 Kagamiyama, Higashi-Hiroshima, Hiroshima 739-8529, Japan \\ **Graduate School of Engineering, Gunma University, 1-5-1 Tenjin-cho, Kiryu, Gunma 376-8515, Japan \\ ***Faculty of Human Life Sciences, Fuji Women's University, Hanakawa, Ishikari, Hokkaido 061-3204, Japan
}

\begin{abstract}
Ion-exclusion chromatography was examined for the simultaneous spectrophotometric determinations of orthophosphate and silicate ions in river water using an ascorbate solution as both an eluent and a reducing agent, followed by postcolumn derivatization using molybdate. The detector responses for both ions increased with increased ascorbic acid concentration in the eluent, but peak tailing was observed for the orthophosphate ion. This suggests that the amounts of undissociated orthophosphate ions increased with decreased eluent $\mathrm{pH}$, resulting in the penetration of the phosphate to the Donnan's membrane formed on the resin surface. Using a neutral sodium ascorbate solution as an eluent, the peak shape was improved. With optimized separation and derivatization conditions (eluent, $20 \mathrm{mM}$ sodium ascorbate; color-forming reagent, $10 \mathrm{mM}$ sodium molybdate- $60 \mathrm{mM}$ sulfuric acid; flow rates of eluent and color-forming reagent, 0.4 and $0.2 \mathrm{~mL}$ $\mathrm{min}^{-1}$; coil length, $6 \mathrm{~m}$ ), the detection limits of orthophosphate and silicate ions were 0.9 and $1.0 \mu \mathrm{g} \mathrm{L}^{-1}$, respectively. This method was successfully applied to the determination of orthophosphate and silicate ions in Kurose River water and the quantitative evaluations of the effects of water intake to a reservoir and discharge from a biological sewage treatment plant on the fluxes of these ions in the river.
\end{abstract}

(Received October 20, 2008; Accepted January 19, 2009; Published March 10, 2009)

\section{Introduction}

Dissolved phosphorus, silicon and nitrogen compounds in water are the required nutrients for phytoplankton growth. Algal growth in semi-closed water areas, such as lakes and estuaries, is frequently stimulated by a high loading of nutrients, such as phosphorus and nitrogen compounds from the surrounding watershed. This can result in a very abundant, dense algal growth, such as blue-green algal blooms and red tides. To reduce eutrophication in freshwater lakes, the focus has been on decreasing the inputs of phosphorus compounds, because a reduced input of nitrogen compounds would not control the eutrophication. ${ }^{1}$ Among phosphorus compounds, the orthophosphate ion is considered to be the most readily available form for aquatic microorganisms. ${ }^{2}$ The phytoplankton diatom species assimilate silicate ions from dissolved silicon to build rigid diatom frustules. Recently, it has been reported that changing the silicate ion supply from the land to estuarine and coastal areas can affect the phytoplankton species composition. ${ }^{3}$ Therefore, the determination of orthophosphate and silicate ions

$\dagger$ To whom correspondence should be addressed.

E-mail:nnakatan@hiroshima-u.ac.jp in water is important for managing the water quality and investigating the environmental factors that affect their concentration and flux.

In general, the spectrophotometric determination of both orthophosphate and silicate ions in water and wastewater is based on the reaction with molybdate to form heteropolyacids, such as molybdophosphate and molybdosilicate, commonly known as molybdenum-yellow and molybdenum-blue. ${ }^{4-6}$ The adsorption spectra of these heteropolyacids are the same, which makes the simultaneous determination of orthophosphate and silicate ions impossible. The standard methods recommend the addition of oxalic acid to destroy the molybdophosphate or tartaric acid to prevent the formation of molybdosilicate, thus avoiding interferences in the determination. ${ }^{4}$ However, these procedures are inconvenient and time-consuming when the determinations of both ions are required.

Ion-exclusion chromatography (IEC) is an effective separation method for weakly basic cations, weakly acidic anions and both cations and anions in various environmental and industrial water samples. ${ }^{7-11}$ The IEC method can be used to separate orthophosphate and silicate ions, because the orthophosphate is mainly present in an ionized form $\left(\mathrm{p} K_{\mathrm{a} 1}=2.15\right)$, and the silicate is not ionized $\left(\mathrm{p} K_{\mathrm{a} 1}=9.83\right)$ in natural water. ${ }^{12}$ However, the sensitivity of determination of the silicate ion is extremely low 
using a conductivity detector, due to the limiting low equivalent ionic conductance. ${ }^{13}$

We have previously reported on the simultaneous determination of orthophosphate and silicate ions using IEC, followed by postcolumn derivatization to molybdenum-yellow and molybdenum-blue and detection using a spectrophotometric detector. ${ }^{14,15}$ Comparing the two methods, the sensitivity for the IEC with molybdenum-blue was relatively better than that with molybdenum-yellow. However, the determination of orthophosphate and silicate ions using IEC with molybdenumblue was complicated by requiring an additional pump for a reducing agent to convert the heteropolyacids into a reduced form, and the baseline noise caused by the three pumps was undesirable. Ultrapure water or diluted sulfuric acid was used as an eluent to separate the orthophosphate and silicate ions in these studies. Using a polymethacrylate-based weakly acidic cation-exchange column comprising carboxylate functional groups fixed on the resin, a solution of weak organic acid is suitable as an eluent for the separation of anions, because the dissociation/protonation of the functional groups, which is related to the ion-exclusion separation mechanism, can be easily controlled. ${ }^{10}$ From this point of view, ascorbic acid $\left(\mathrm{p} K_{\mathrm{a} 1}=\right.$ 4.10), which was used as a reducing agent in the molybdenumblue method, can be used as an eluent due to its weak acidity.

In this work, the simultaneous spectrophotometric determination of orthophosphate and silicate ions using IEC with postcolumn derivatization was investigated using an ascorbate solution as both the eluent and the reducing agent. This resulted in the ions being completely separated and detected following postcolumn derivatization. Furthermore, the baseline noise and sensitivity were improved due to the simplified system. The effectiveness of this method was demonstrated by water-quality monitoring of orthophosphate and silicate ions in practical water samples.

\section{Experimental}

\section{Reagents}

All reagent-grade or analytical-grade chemicals used in this study were obtained from Wako Chemicals Co. (Osaka, Japan). Commercial standard solutions of orthophosphate ions (100 mg $\mathrm{L}^{-1}$ as $\mathrm{P}$ ) and silicate ions (1000 $\mathrm{mg} \mathrm{L}^{-1}$ as $\mathrm{Si}$ ) were used as stock standard solutions. For the eluent, ascorbic acid, sodium ascorbate or a mixture of the two was used. A solution of sulfuric acid and sodium molybdate was used as a color-forming reagent. Ultrapure water $(>18 \mathrm{M} \Omega \mathrm{cm}$ ) was used to prepare the standard and reagent solutions.

\section{Apparatus}

A Tosoh ion chromatograph system consisting of two pumps (DP-8020), an on-line degasser (SD-8022), a column oven (CO8020) and a spectrophotometric detector (UV-8020) was used. This system was controlled by a Tosoh chromatographic workstation, LC-8020 Model II. The injector was a manual sixway valve equipped with a $100-\mu \mathrm{L}$ sample loop. The separation column used in this study was a Tosoh TSKgel Super IC-A/C $(150 \mathrm{~mm} \times 6.0 \mathrm{~mm}$ i.d.) packed with a polymethacrylate-based weakly acidic cation-exchange resin $\left(0.2\right.$ meq. $\mathrm{mL}^{-1}$ cationexchange capacity). Derivatization with the color-forming reagent occurred in a reaction coil. The flow line and reaction coil were made from polyetheretherketone (PEEK) tubing with an internal diameter of $0.25 \mathrm{~mm}$. Both the column and the reaction coil were kept in the column oven at $45^{\circ} \mathrm{C}$. The typical flow rates of the eluent and the color-forming reagent were 0.4

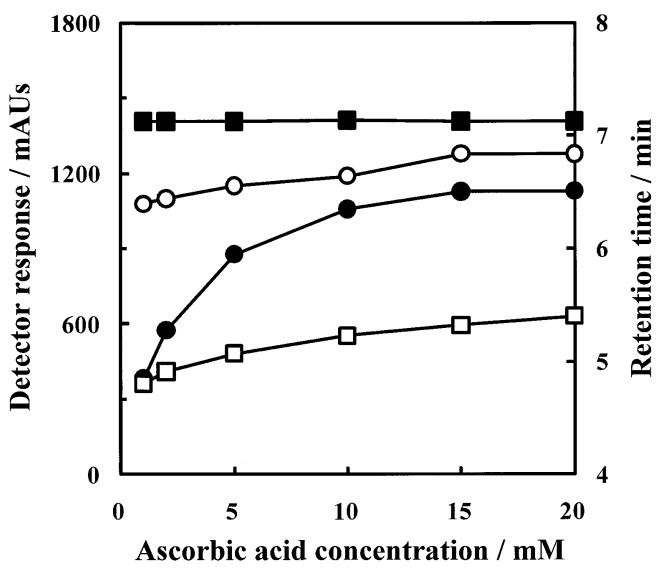

Fig. 1 Effect of the ascorbic acid concentration in the eluent on the detector responses (peak area) and the retention times for orthophosphate and silicate ions. Analytical conditions: separation column, TSKgel super IC-A/C; reaction coil, PEEK tubing $(0.25 \mathrm{~mm}$ i.d. $\times 6 \mathrm{~m}$ ); column oven temperature, $45^{\circ} \mathrm{C}$; color-forming reagent, $10 \mathrm{mM}$ sodium molybdate-50 mM sulfuric acid; eluent flow, $0.4 \mathrm{~mL}$ $\mathrm{min}^{-1}$; flow rate of color-forming reagent, $0.2 \mathrm{~mL} \mathrm{~min}^{-1}$; both of orthophosphate and silicate ion concentration, $1000 \mu \mathrm{g} \mathrm{L}^{-1}$. Lines: $\bigcirc$, detector response for orthophosphate ion; $\bullet$, detector response for silicate ion; $\square$, retention time of orthophosphate ion; $\mathbf{\square}$, retention time of silicate ion.

and $0.2 \mathrm{~mL} \mathrm{~min}^{-1}$, respectively. The wavelength of the detector was set at $700 \mathrm{~nm}$.

\section{Water samples}

River-water samples were collected from the Kurose River watershed, and a discharged water sample was collected from a biological sewage treatment plant in Hiroshima prefecture, western Japan on 23 July 2008. The Kurose River is a small river, and the discharge from the treatment plant is a significant source of orthophosphate in the watershed. ${ }^{15}$ When water sampling was carried out, the flow rate was measured using a propeller anemometer (Katsushima Seiki Ltd.), and the depth of the sites at each cross section was recorded. ${ }^{16}$ From the waterflow rates and cross-sectional areas, the river-water flux for each sampling point was calculated in order to determine the flux of orthophosphate and silicate ions. After filtration through a hydrophilic polytetrafluoroethylene (PTFE) syringe filter with a $0.2 \mu \mathrm{m}$ pore size (DISMIC ${ }^{\circledR}-25_{\mathrm{HP}}$, Advantec Toyo Kaisha, Ltd.), the water samples were stored in a dark room at $5^{\circ} \mathrm{C}$ until analysis.

\section{Results and Discussion}

Effect of the ascorbate solution as an eluent on the separation and the detector responses for orthophosphate and silicate ions

The effect of the ascorbic acid concentration in the eluent on the retention times and the detector responses (peak area) for the orthophosphate and silicate ions are shown in Fig. 1. The retention time of the orthophosphate ions increased slightly as the ascorbic acid concentration increased from 1 to $20 \mathrm{mM}$, but a greater degree of peak tailing was observed at higher ascorbic acid concentrations. The retention time and the peak shape of the silicate ions remained unchanged. As the ascorbic acid concentration increased, the $\mathrm{pH}$ value of eluent decreased from 3.65 to 3.02 . The increasing retention time and the peak tailing of the orthophosphate ions with increasing ascorbic acid concentration were due to the ion-exclusion mechanism and 


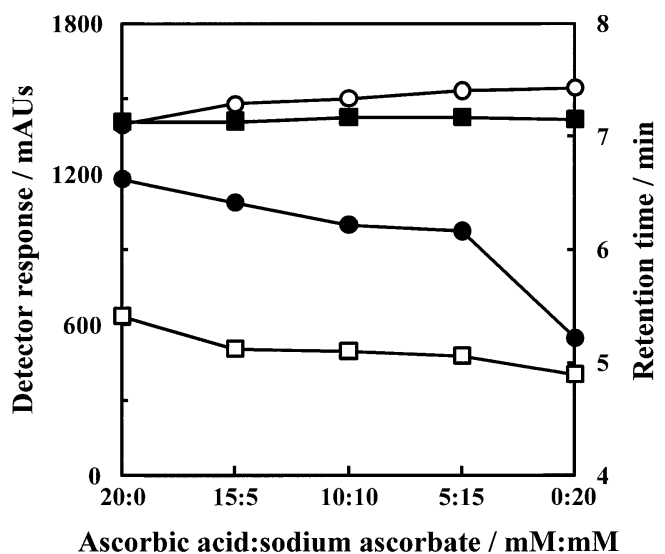

Fig. 2 Effect of the ratios of ascorbic acid to sodium ascorbate in the eluent on the detector responses (peak area) and the retention times for orthophosphate and silicate ions. Analytical conditions: total ascorbate concentration, $20 \mathrm{mM}$. The other conditions are in Fig. 1. Lines: $O$, detector response for orthophosphate ion; detector response for silicate ion; $\square$, retention time of orthophosphate ion; $\mathbf{\square}$, retention time of silicate ion.

dissociation of the orthophosphate ions related to the eluent acidity. This resulted in the penetration of orthophosphate ions into the Donnan's membrane that formed on the resin surface. The detector responses for both ions increased as the concentrations of ascorbic acid increased to $15 \mathrm{mM}$, and they remained unchanged at ascorbic acid concentrations above $15 \mathrm{mM}$.

To improve the peak resolution and to reduce the peak tailing of the orthophosphate ions caused by the eluent acidity, a buffer solution of ascorbic acid and sodium ascorbate was used as an eluent with a constant concentration of $20 \mathrm{mM}$ of the total ascorbate. The retention time of the orthophosphate ions decreased somewhat when there was a high proportion of sodium ascorbate in the eluent, and the peak tailing was improved. The retention time of the silicate ions remained unchanged (Fig. 2). When a $20 \mathrm{mM}$ sodium ascorbate solution ( $\mathrm{pH}$ 6.47) was used as the eluent, the detector response for the orthophosphate ions at $1000 \mu \mathrm{g} \mathrm{L}^{-1}$ was the highest, while the response for the silicate ions was the lowest. The concentration of silicate ions has been observed at levels of several thousand $\mu \mathrm{g} \mathrm{L}^{-1}$ in river water, while the concentrations of orthophosphate are often observed at less than $100 \mu \mathrm{g} \mathrm{L}^{-1}{ }^{15}$ In addition, the detector response for the silicate ions could be improved by comparing the color-forming reagents, as described in a later section. Therefore, a solution of $20 \mathrm{mM}$ sodium ascorbate was used as an eluent in this study to prioritize the detector response for orthophosphate ions over that for silicate ions.

Optimization of spectrophotometric detection for orthophosphate and silicate ions after ion-exclusion chromatographic separation

With a solution of $20 \mathrm{mM}$ sodium ascorbate being used as an eluent, optimization of the color-forming reagent containing sodium molybdate and sulfuric acid was examined. Figure 3 shows the effect of varying the sodium molybdate concentration in a color-forming reagent containing $60 \mathrm{mM}$ sulfuric acid on the detector responses for the orthophosphate and silicate ions. The detector response for the orthophosphate ions increased slightly when the sodium molybdate concentration in the reagent was increased, whereas the response of silicate ions increased remarkably. However, the detector response for both the orthophosphate and silicate ions decreased when the sodium molybdate concentration exceeded $30 \mathrm{mM}$. Additionally, when

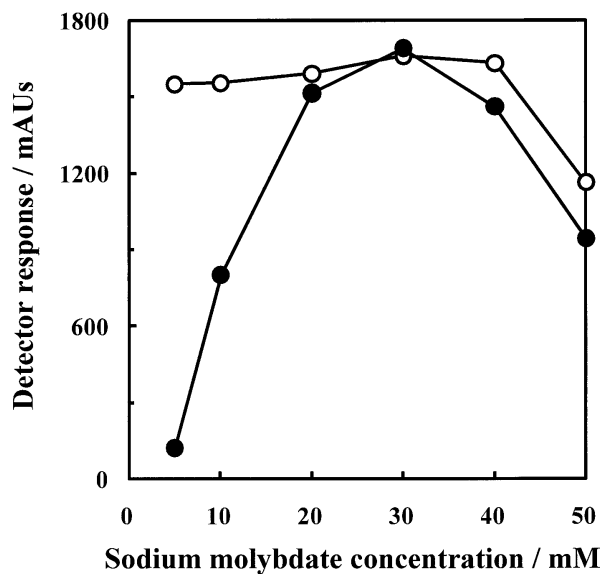

Fig. 3 Effect of the sodium molybdate concentration in the colorforming reagent on the detector responses (peak area) for orthophosphate and silicate ions. Analytical conditions: eluent, 20 $\mathrm{mM}$ sodium ascorbate; color-forming reagent, sodium molybdate-60 $\mathrm{mM}$ sulfuric acid. The other conditions are as in Fig. 1. Lines: $O$, orthophosphate ion; $\bullet$, silicate ion.

ultrapure water was injected as a blank, a peak was observed at the same retention time as the orthophosphate ions, and the peak area of the blank exceeded $2 \%$ of that for the $1000 \mu \mathrm{g} \mathrm{L}^{-1}$ orthophosphate ions when the sodium molybdate concentrations exceeded $20 \mathrm{mM}$. From these results, the optimal sodium molybdate concentration in the color-forming reagent was determined to be $10 \mathrm{mM}$.

The effect of the sulfuric acid concentration in the colorforming reagent containing $10 \mathrm{mM}$ sodium molybdate on the detector response of both ions was also examined. The detector responses for both ions increased with increasing sulfuric acid concentration to a concentration of $60 \mathrm{mM}$, and the responses remained unchanged at higher concentrations. Therefore, the sulfuric acid concentration in the reagent was fixed at $60 \mathrm{mM}$.

The effects of the eluent flow rate and the reaction coil length on the retention time and the detector responses for the orthophosphate and silicate ions were examined. In this study, the flow rate of the color-forming reagent was set at half that of the eluent flow rate. With a 6-m long reaction coil, the detector responses for both ions increased as the eluent flow rate decreased from 1.0 to $0.1 \mathrm{~mL} \mathrm{~min}^{-1}$, while the retention times of both ions increased. With the eluent flow rate maintained at a constant $0.4 \mathrm{~mL} \mathrm{~min} \mathrm{~m}^{-1}$, the detector responses for both ions increased linearly as the length of the reaction coil was increased from 1 to $10 \mathrm{~m}$. These results indicate that the formation rate of heteropolyacids, such as molybdophosphate and molybdosilicate, is relatively slow. As in previous studies, it should be noted that the selection of a lower eluent flow rate and/or a longer reaction coil length is an effective way to obtain highly sensitive detection of both orthophosphate and silicate ions. ${ }^{14,15}$ For the purpose of a comparison with the analytical performance of previous studies, the optimized eluent flow rate and the reaction coil length in this study were set at $0.4 \mathrm{~mL} \mathrm{~min}^{-1}$ and $6 \mathrm{~m}$, respectively.

Using these optimized analytical conditions for the simultaneous determination of orthophosphate and silicate ions, good separation of these ions was achieved, as shown in Fig. 4.

\section{Analytical performance}

The calibration curves were linear in the concentration range $10-1000 \mu \mathrm{g} \mathrm{L}^{-1}$ as $\mathrm{P}$ for the orthophosphate ions $\left(r^{2}=0.9998\right)$ 


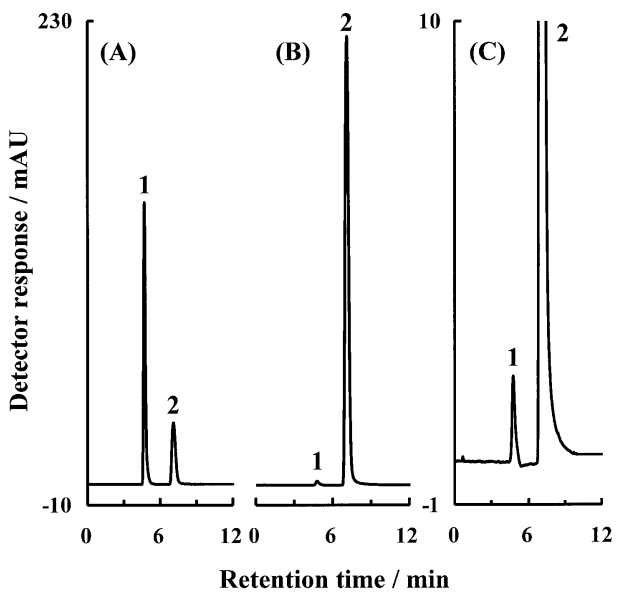

Fig. 4 Typical chromatogram of orthophosphate and silicate ions obtained using optimized chromatographic conditions. Analytical conditions: eluent, $20 \mathrm{mM}$ sodium ascorbate; color-forming reagent, $10 \mathrm{mM}$ sodium molybdate- $60 \mathrm{mM}$ sulfuric acid. The other conditions are as in Fig. 1. (A) Standard solution of $1000 \mu \mathrm{g} \mathrm{L}^{-1}$ as $\mathrm{P}$ and Si for both ions, (B) river water and (C) a close-up view of the river water. Peaks: 1, orthophosphate ion; 2 , silicate ion.

and $10-5000 \mu \mathrm{g} \mathrm{L}^{-1}$ as $\mathrm{Si}$ for the silicate ions $\left(r^{2}=0.9995\right)$ using the optimized analytical conditions in this study.

The detection limits of orthophosphate and silicate ions corresponded to three-times the standard deviation of triplicate injections of both ions at $5 \mu \mathrm{g} \mathrm{L}^{-1}$ standard solution, and were 0.9 and $1.0 \mu \mathrm{g} \mathrm{L}^{-1}$, respectively. These detection limits were somewhat improved compared with our previous studies using a two-pump system with molybdenum-yellow and a three-pump system with molybdenum-blue. ${ }^{14,15}$ The improvements are due to a reduced total flow rate and lower baseline noise from the simplified system.

Ten replicate chromatographic runs for both orthophosphate and silicate ions at $10 \mu \mathrm{g} \mathrm{L}^{-1}$ were undertaken, and the relative standard deviations of the peak area were 0.54 and $5.86 \%$, respectively, and the relative standard deviations of the retention time were 0.18 and $0.26 \%$, respectively.

The recovery tests were performed by the addition of $0.1 \mu \mathrm{g}$ as $\mathrm{P}$ for orthophosphate ions and $2 \mu \mathrm{g}$ as $\mathrm{Si}$ for silicate ions to five different river-water samples. Good results for both orthophosphate and silicate ions were obtained with recoveries in the range of 95.7 to $101.6 \%$ (mean \pm S.D., $97.6 \pm 2.4 \%$ ) and 95.5 to $102.9 \%$ (mean \pm S.D., $99.3 \pm 3.5 \%$ ), respectively.

Application to water quality monitoring for orthophosphate and silicate ions in river water and discharged water from a biological sewage treatment plant

The method developed in this study was used to investigate the water quality in the Kurose River watershed, in the city of Higashi-Hiroshima, in western Japan. The concentrations of orthophosphate and silicate ions in the river were observed in the ranges of 14 to $401 \mu \mathrm{g} \mathrm{L}-1$ and 4840 to $9290 \mu \mathrm{g} \mathrm{L}^{-1}$, respectively. As mentioned in our previous study, the concentrations of the orthophosphate ions increased dramatically downstream of the discharge from a biological sewage treatment plant, while the concentrations of the silicate ions decreased slightly from upstream to downstream. ${ }^{15}$

The fluxes of orthophosphate and silicate ions at each sampling point were determined from the water flux and their concentrations in order to evaluate the effect of water intakes from the river to the reservoir and discharge from the treatment

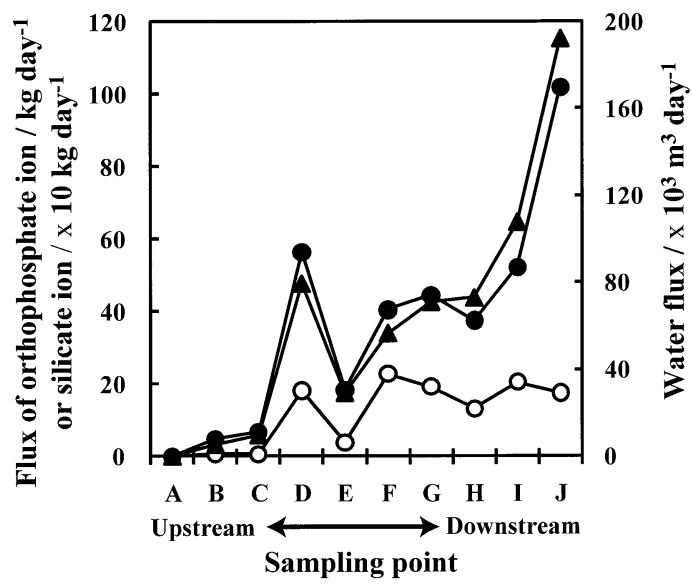

Fig. 5 Distribution of water flow, orthophosphate ion and silicate ion flux from upstream to downstream of Kurose River. Lines: $\boldsymbol{\Delta}$, water flow flux; $\bigcirc$, orthophosphate ion flux; $\bullet$, silicate ion flux.

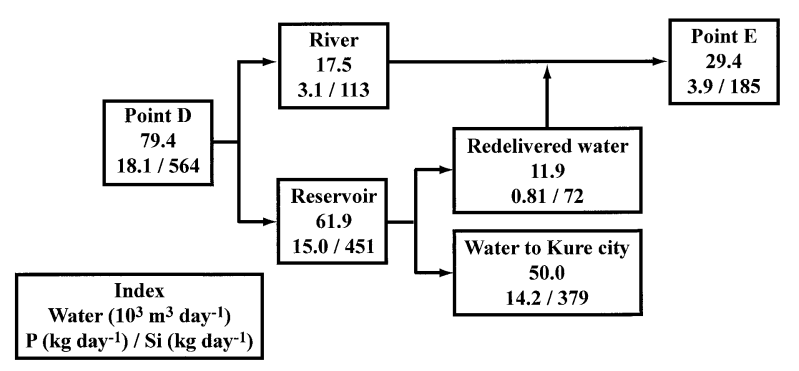

Fig. 6 Mass balance flow of water, orthophosphate ions and silicate ions at the points between $\mathrm{D}$ and $\mathrm{E}$.

plant into the river. Figure 5 shows the fluxes of water, the orthophosphate ions and the silicate ions from upstream to downstream on the Kurose River. The flux of orthophosphate ions was dependent on the water flux between sampling points A to $F$, and then remained fairly constant downstream, suggesting that the transformation of dissolved orthophosphate ions to an insoluble form may be occurring through absorption to the sediment and biotic uptake in the river water of the downstream area. However, the variation of the silicate ion flux depended almost entirely on the water flux. It could be suggested that silicate ions are comparatively insusceptible to biological and physicochemical factors when flowing with water in a river.

The fluxes of orthophosphate and silicate ions corresponding to the water flow dramatically decreased between points $\mathrm{D}$ and E due to a water intake from the Kurose River to the Minaga Reservoir, where most of the impounded water is supplied to the city of Kure. Using the measured concentrations and water flux at the sampling points, including the point where water is redelivered from the reservoir to the river, the mass balance values of water, orthophosphate ions and silicate ions at the points from D to E were calculated; results are shown in Fig. 6. Removal of the orthophosphate ions from the Kurose River water due to the water intake from the river through the reservoir to Kure city was $78.5 \%$, while the water flow and silicate ions were reduced by 63.0 and $67.2 \%$, respectively. These results suggested that orthophosphate ions in river water are removed by biological and physicochemical processes, such as absorption and biotic uptake in the reservoir. Consequently, the concentration of orthophosphate ions in redelivered water 
Table 1 Summary of water, orthophosphate ion and silicate ion fluxes between points $\mathrm{E}$ and $\mathrm{F}$ and their discharge amounts from a biological sewage treatment plant

\begin{tabular}{lccc}
\hline \multicolumn{1}{c}{ Parameter } & Unit & $\begin{array}{c}\text { Flux between } \\
\text { points E and F }\end{array}$ & $\begin{array}{c}\text { Discharge amount } \\
\text { from a biological } \\
\text { sewage treatment } \\
\text { plant }\end{array}$ \\
\hline Water & $\times 10^{3} \mathrm{~m}^{3} \mathrm{day}^{-1}$ & 27.4 & 31.4 \\
$\begin{array}{l}\text { Orthophosphate } \\
\text { ion }\end{array}$ & $\mathrm{kg} \mathrm{P} \mathrm{day}^{-1}$ & 18.8 & 18.8 \\
Silicate ion & $\mathrm{kg} \mathrm{Si} \mathrm{day}^{-1}$ & 220 & 263 \\
\hline
\end{tabular}

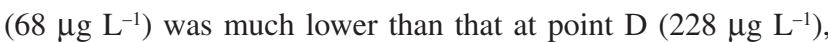
resulting in a reduction of the concentration in the main river at point $\mathrm{E}\left(133 \mu \mathrm{g} \mathrm{L} \mathrm{L}^{-1}\right)$.

The fluxes of both ions increased between points $\mathrm{E}$ and $\mathrm{F}$ (the distance between the points is approximately $600 \mathrm{~m}$ ), because there is discharge from a biological sewage treatment plant between the points, and the concentrations of the orthophosphate and silicate ions in the discharged water were 600 and $8370 \mu \mathrm{g}$ $\mathrm{L}^{-1}$, respectively. The discharge amounts of orthophosphate and silicate ions from the treatment plant were estimated from the measured concentrations in the discharged water and the average water discharge amount for 2007 obtained from an annual report of the treatment plant $\left(31.4 \times 10^{3} \mathrm{~m}^{3}\right.$ day $\left.^{-1}\right)$, as well as their fluxes, which were calculated from the differences in the fluxes between points $\mathrm{E}$ and $\mathrm{F}$. These results are summarized in Table 1. The discharge amounts of orthophosphate and silicate ions from the treatment plant were consistent with their fluxes between the points $\mathrm{E}$ and $\mathrm{F}$, demonstrating that the discharge from the treatment plant was a significant source of both orthophosphate and silicate ions to the river between points $\mathrm{E}$ and $\mathrm{F}$.

\section{Conclusion}

Using an ascorbate solution as an eluent, the IEC system with postcolumn derivatization using molybdate was simplified, and the detection limit was improved due to a reduction of the total system flow and the baseline noise. The present method for the simultaneous determination of orthophosphate and silicate ions is effective for use in practical applications to water-quality monitoring.

\section{Acknowledgements}

The authors wish to thank Ms. Asami Ogura, a doctoral course student, Hiroshima University, for lending a propeller anemometer. This work was financially supported by commissioned research of the Chugoku Regional Development Bureau of the Ministry of Land, Infrastructure, Transport and Tourism.

\section{References}

1. D. W. Schindler, R. E. Hecky D. L. Findlay, M. P. Stainton, B. R. Parker, M. J. Paterson, K. G. Beaty, M. Lyng, and S. E. M. Kasian, Proc. Natl. Acad. Sci. U. S. A., 2008, 105, 11254.

2. K. Björkman and D. M. Karl, Mar. Ecol. Prog. Ser., 1994, $111,265$.

3. V. Ittekkot, C. Humborg, and P. Schäfer, Bioscience, 2000 , 50,776 .

4. L. S. Clesceri, A. E. Greenberg, and P. R. Trussell (ed.), "Standard Methods for the Examination of Water and Wastewater", 17th ed., 1989, APHA-AWWA-WFE, Washington, D.C.

5. JIS K 0101, "Testing Methods for Industrial Water", 1998, Japanese Industrial Standard Committee, Tokyo.

6. JIS K 0102, "Testing Methods for Industrial Wastewater", 2008, Japanese Industrial Standard Committee, Tokyo.

7. M. Mori, K. Tanaka, M. I. H. Helaleh, Q. Xu, M. Ikedo, Y. Ogura, S. Sato, W. Hu, and K. Hasebe, J. Chromatogr., A, 2003, 997, 191

8. M. Mori, H. Itabashi, M. I. H. Helaleh, K. Kaczmarski, B. Głód, T. Kowalska, Q. Xu, M. Ikedo, W. Hu, and K. Tanaka, J. Chromatogr., A, 2006, 1118, 41.

9. K. Ito, Y. Takayama, M. Ikedo, M. Mori, H. Taoda, Q. Xu, W. Hu, H. Sunahara, T. Hayashi, S. Sato, T. Hirokawa, and K. Tanaka, J. Chromatogr., A, 2004, 1039, 141.

10. M. Mori, K. Tanaka, T. Satori, M. Ikedo, W. Hu, and H. Itabashi, J. Chromatogr., A, 2006, 1118, 51.

11. D. Kozaki, R. Goto, W. Masuda, D. Saito, N. Nakatani, N. Nakagoshi, M. Mori, and K. Tanaka, Bunseki Kagaku, 2008, 57, 651.

12. W. Stumm and J. J. Morgan, "Aquatic Chemistry: Chemical Equilibria and Rates in Natural Waters", 3rd ed., 1996, John Wiley and Sons, New York.

13. M. Mori, K. Tanaka, H. Taoda, M. Ikedo, and W. Hu, Bunseki Kagaku, 2004, 53, 1481.

14. M. Ikedo, M. Mori, K. Kurachi, W. Hu, and K. Tanaka, Anal. Sci., 2006, 22, 117.

15. N. Nakatani, D. Kozaki, W. Masuda, N. Nakagoshi, K. Hasebe, M. Mori, and K. Tanaka, Anal. Chim. Acta, 2008, $619,110$.

16. JIS K 0094, "Sampling Methods for Industrial Water and Industrial Wastewater", 1994, Japanese Industrial Standard Committee, Tokyo. 